\title{
To study the level of congestion in Pre anesthetic Check up (PAC) clinic and use of Self-answering Pre-operative questionnaire to decongest it
}

\author{
Kumar Singh M. ${ }^{1}$, Bhatia K. ${ }^{2 *}$, Tobin R. ${ }^{3}$, Waindeskar V. ${ }^{4}$, Kumar A. ${ }^{5}$, Sharma . $^{6}$ \\ DOI: https://doi.org/10.17511/ijmrr.2019.i01.02
}

1 Manish Kumar Singh, Assistant Professor, SHKM Govt. Medical College Nalhar, Mewat, Haryana, India.

2* Kiran Bhatia, Associate Professor, Department of Anaesthesiology, SHKM Government Medical College, Gehbar, Haryana, India.

3 Raj Tobin, Director Anaesthesia, SHKM Govt. Medical College Nalhar, Mewat, Haryana, India.

${ }^{4}$ Vaishal Waindeskar, Professor \& HOD, All India Institute of Medical Sciences (AIIMS), Bhopal, Madhya Pradesh, India.

5 Amit Kumar, Professor \& HOD, Department of Anaesthesia, SHKM Govt. Medical College Nalhar, Mewat, Haryana, India.

6 Punit Sharma, Senior Consultant, Max Hospital, New Delhi, India.

Background: Aim of the study was to reduce congestion in PAC clinic, which is the direct indicator of efficiency of the hospital. 1) To study overall waiting time in the PAC clinic. 2) To suggest action to improve the waiting time in PAC. Methods: Prospective, Descriptive study, 40 patients in each group. Group "R" = Patients registered for PAC clinic, who's all vitals and clinical assessment was done after arrival to PAC clinic as routine practice. Group " $Q$ " = Patients were provided Selfanswering Pre-operative in waiting area and whose vital parameters were taken before arrival to PAC clinic by a trained staff. Data was recorded for both the groups. Results: We found in our study that average waiting time that is total time from registration to completion of PAC in OPD clinic was statistically significantly less in QT-1 (Group "Q") in comparison to RT-1 (Group "R"). We found in our study that average Doctor - Patient time that is time of interaction with Doctor during PAC in OPD clinic was also statistically significantly less in QT-2 (Group "Q") in comparison to RT-2 (Group "R"). Conclusion: Present study was planned to reduce congestion in OPD for pre-anesthesia checkup for elective surgery or procedure. Patient satisfaction comes automatically as a byproduct with the achievement of the goal of the study. Time is money in the present scenario and thus best utilization of time with efficient outcome is the prerequisite of any good management.

Keywords: Pre-anesthesia checkup, outpatient department clinic, OPD Congestion

Corresponding Author

Kiran Bhatia, Associate Professor, Department of Anaesthesiology, SHKM Government Medical College, Gehbar, Haryana, India.

Email: drkiran41@gmail.com
How to Cite this Article

Singh MK, Bhatia K, Tobin R, Waindeskar V, Kumar A, Sharma $P$. To study the level of congestion in Pre anesthetic Check up (PAC) clinic and use of Selfanswering Pre-operative questionnaire to decongest it. Int J Med Res Rev. 2019;7(1):8-12.

Available From

https://ijmrr.medresearch.in/index.php/ijmrr/article/ view/1028
To Browse

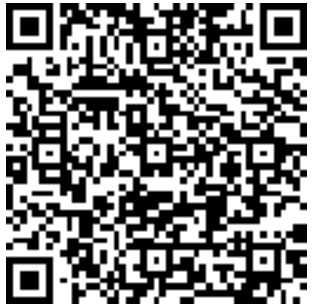

Manuscript Received 2019-01-04

Conflict of Interest No
Review Round 1 2019-01-14

Funding

Review Round 2
2019-01-20
Ethical Approval
Yes

Review Round 2

Yes
Review Round 3

Plagiarism X-checker $6 \%$
Accepted 2019-01-25

Note

() 2019 by Manish Kumar Singh, Kiran Bhatia, Raj Tobin, Vaishal Waindeskar, Amit Kumar, Punit Sharma and Published by Siddharth Health Research and Social Welfare Society. This is an Open Access article licensed under a Creative Commons Attribution 4.0 International License https://creativecommons.org/licenses/by/4.0/ unported [CC BY 4.0] 


\section{Introduction}

Pre-anesthesia checkup or evaluation (PAC) is defined as the process of clinical evaluation that precedes anesthetic care, which are necessary for the realization of the surgery or non-surgical procedure. Unlike other medical specialty PAC is elaborated and time consuming through systemic clinical examination of patient with aim to optimize patient condition depending upon the type and urgency of surgery to administer safe anesthesia.

Urgency of surgical need always compromise with optimization of patients co-morbidities and thus increases the risk during anesthesia and surgery [1]. Among the advantages of PAC are included a reduction in morbidity and increase in the quality of the anesthetic- surgical procedure. Elective outpatient PAC also promotes a reduction in patient anxiety and cancelation of surgeries $[2,3,4]$. Patients coming to OPD (outpatient department) PAC are usually for elective surgeries and thus need detailed clinical examination with special attention to co morbidities, if any. It is usually seen that there is increased waiting time or queuing congestion in PAC clinics. OPD congestion is usually correlated with patient dis-satisfaction.

There are many studies and management techniques have been used to improve patient satisfaction. This paradoxical situation where OPD congestion needs to be reduced without compromising the elaborate clinical assessment has rarely been taken care of in previous studies. This study has been formulated primarily keeping in view the optimal management of waiting time with maximum efficient output. The relevant significant information can be gathered by Anesthesiologist in PAC clinic quickly through filling of self-answered pre-operative questionnaires by the patient whose vital parameters have been already checked before arrival to clinic.

\section{Materials and Methods}

The study was conducted at Max Super Specialty Hospital, Saket, New Delhi. The hospital is a 521 bedded tertiary care hospital with good number of surgeries being done every day. Study population was taken from the patients registered in the PAC clinic for elective surgical procedures.

Study Design: Prospective, Descriptive study.

Sample size: 40 patients in each group.
Randomization: Was done by alternate registration for PAC in to two groups that is group " $\mathrm{R}^{\text {" and group }}$ "Q".

Group "R" = Patients registered for PAC clinic, who's all vitals and clinical assessment were done after arrival to PAC clinic as routine practice.

Group "Q" = Patients who wereprovided Selfanswering Pre-operative questionnaire (Appendix1or Appendix-2 i.e. - Hindi version) in waiting area and whose vital parameters such as BP (blood pressure), Pulse rate, Respiratory rate, Temperature, Height, Weight, and $\mathrm{SpO} 2$ (oxygen saturation at room air) were taken before arrival to PAC clinic by a trained staff.

Data: recorded for both the groups-

01. RT-1 =Average Patient waiting Time in PAC clinic, that is total time from registration to completion of PAC.

02. QT-1 = Average Patient waiting Time in PAC clinic, that is total time from registration to completion of PAC.

03. RT-2 =Average Doctor - Patient Time, that is total time of doctor-patient interaction.

04. QT-2 =Average Doctor - Patient Time, that is total time of doctor-patient interaction.

\section{Inclusion Criteria}

01. Patients who are willing to participate.

02. Age 18 to 65 years.

03. Clinically stable patient with one or two controlled systemic comorbidities.

04. Understands English or Hindi scripts.

\section{Exclusion criteria}

01. Unwilling patient.

02. Language barrier.

03. Cognitive instability.

04. Extremes of age group (Less than 18 years and more than 65 years).

05. Patients with multiple comorbidities or patients requiring other specialty intervention first.

Statistical Analysis- Data collected from both the groups will be cleared, sorted and entered in to Microsoft EXCEL. After data entry, various statistical analyses will be done, such as Average waiting time, Average Doctor- Patient time, mean median patient waiting time etc. 
This will provide statistical results for the study. SPSS (version 17.0, Chicago, IL, USA) was used for statistical analysis and continuous variables were noted as mean \pm standard deviation, VAS as mean \pm standard error and analyzed using ANOVA. Waiting times with there values were calculated using "paired T tests". Categorical variables were noted in number of patients (\%) and analyzed using chi-squared and Fisher's exact test. A P value of < 0.05 was considered statistically significant and $P$ value of $<0.01$ was highly significant were taken.

\section{Results}

Table-1: Average end point observation.

\begin{tabular}{|l|l|l|l|}
\hline Group & \multicolumn{1}{|c|}{$\begin{array}{c}\text { Average waiting time of } \\
\text { complition of PAC (In minutes) }\end{array}$} & P Value & Significance \\
\hline $\begin{array}{l}\text { RT-1 } \\
\text { (Group- } \\
\text { R) }\end{array}$ & 73.925 & $\begin{array}{l}\text { less than } \\
\text { extremely }\end{array}$ & $\begin{array}{l}\text { statistically } \\
\text { significant }\end{array}$ \\
\hline $\begin{array}{l}\text { QT-1 } \\
\text { (Group- } \\
\text { Q) }\end{array}$ & 51.825 & less than & $\begin{array}{l}\text { extremely } \\
\text { statistically } \\
\text { significant }\end{array}$ \\
\hline
\end{tabular}

We found in our study that average waiting time that is total time from registration to completion of PAC in OPD clinic was statistically significantly less in QT-1 (Group "Q") in comparison to RT-1 (Group " $R$ "). The two-tailed $P$ value is less than 0.0001. By conventional criteria, this difference is considered to be extremely statistically significant.

Table-2: Average end point observation.

\begin{tabular}{|l|l|l|l|}
\hline Group & $\begin{array}{c}\text { Average Doctor -Patient Time } \\
\text { In PAC (In Minutes) }\end{array}$ & P Value & \multicolumn{1}{|c|}{ Significance } \\
\hline $\begin{array}{l}\text { RT-2 } \\
\text { (Group- } \\
\text { R) }\end{array}$ & 22.525 & $\begin{array}{l}\text { less than } \\
0.0001\end{array}$ & $\begin{array}{l}\text { extremely } \\
\text { statistically } \\
\text { significant }\end{array}$ \\
\hline $\begin{array}{l}\text { QT-2 } \\
\text { (Group- }\end{array}$ & 15.6 & less than & extremely \\
Q) & & 0.0001 & $\begin{array}{l}\text { statistically } \\
\text { significant }\end{array}$ \\
\hline
\end{tabular}

We found in our study that average Doctor - Patient time that is time of interaction with Doctor during PAC in OPD clinic was also statistically significantly less in QT-2 (Group "Q") in comparison to RT-2 (Group " $R$ "). The two-tailed $P$ value is less than 0.0001 By conventional criteria, this difference is considered to be extremely statistically significant.

\section{Clinical parameters distribution results}

01. Average mean blood pressure in both the groups that is Group " $\mathrm{R}$ " and Group " $\mathrm{Q}$ " were found statistically comparable in our study project.
02. Average respiratory rate in study population of both of the group that is Group " $\mathrm{R}$ " and " $\mathrm{Q}$ " were found comparable statistically in our project.

03. We found average body temperature was statistically comparable in both the groups that is in Group- $\mathrm{R}$ and Group- $\mathrm{Q}$ of our study population.

04. Average room air oxygen saturation in study population of both of the group that is Group " $\mathrm{R}$ " and " $\mathrm{Q}$ " were found comparable statistically in our project.

End point results: We found in our study that average waiting time that is total time from registration to completion of PAC in OPD clinic was statistically significantly less in QT-1 (Group "Q") in comparison to RT-1 (Group "R"). We found in our study that average Doctor - Patient time that is time of interaction with Doctor during PAC in OPD clinic was also statistically significantly less in QT-2 (Group "Q") in comparison to RT-2 (Group "R").The two-tailed $P$ value is less than 0.0001. By conventional criteria, this difference is considered to be extremely statistically significant.

\section{Discussion}

Patient waiting time for healthcare services is identified by the World Health Organization (WHO) as one of the key measurements of a responsive health system. Patient waiting time is the amount of time for patients seeking care at healthcare units before being attended for consultation and treatment $[5,6]$.

In our project although we have able to reduce congestion time statistically significantly to 51.825 minutes from average 73.925 minutes but still we are far from the Patient's Charter of the United Kingdom (UK) Government [7].

Michael $M$, Egan $P L$, et al. worked on how to improve wait times and patient satisfaction in primary care. Katre AN studied assessment of the correlation between Appointment Scheduling and Patient Satisfaction in a Pediatric Dental Setup. Helbig M, Helbig S, Kahla-Witzsch HA, et al. did quality management by reduction of waiting time and efficiency enhancement in an ENT-university outpatients' department. Similar work was done by Pitrou I, Lecourt AC, Bailly $L$, et al. They worked on Waiting time and assessment of patient satisfaction in a large reference emergency department: 
A prospective cohort study.So all the above studies are similar to our study as they all were aimed at reducing wait time and effective and smooth running of the out patient department. [8 -11]. The Patient's Charter of the United Kingdom (UK) Government sets a series of standards which state that all patients must be seen within 30 min of their appointment time. Other authors also found that reduced outpatient waiting times with improved appointment scheduling is possible $[12,13,14]$.

Huang found that outpatients were reasonably satisfied if they waited no more than 37 minutes when arriving on time. Our results are not in line with this threshold finding by Huang. Though with the measures we have applied were able to reduce waiting time has statistically significantly from routine average waiting time of 73.925 minutes to 51.825 minutes. Thus our results have achieved the aim to reduce congestion in PAC clinic OPD at Max Hospital, Saket, New Delhi. Of Corse there is further scope to improvement in waiting time reduction in future with more interventions in the studied hospital as it is not a one-time campaign but continuous efforts [15].

We found in our study the average Doctor - Patient time were always higher in both the groups that is Group " $\mathrm{R}$ " that is "RT-2" (22.525 minutes) \&Group "Q" that is "QT-2" (15.6 minutes) than the (6.6 \pm $3.7 \mathrm{~min}$ ) of Ranjeeta et al study. But as appears from the results in our study higher Doctor-Patient time in that is "RT-2" than "QT-2" is not correlated with greater patient satisfaction as this time has been used in activities such as taking clinical parameters and Patients past clinical history which were not prudent to consume Doctor- Patient time.

Also this statistically significant reduction of DoctorPatient time by implementing the measures to reduce this high value time of Doctor and Patient without compromising the quality of Healthcare services and Patient satisfaction. Thus, quality of healthcare improvement is achieved by effectiveness of the interventions by providing Selfanswering Pre-operative questionnaire in waiting area and whose vital parameters were taken before arrival to PAC clinic by a trained staff to reduce overall waiting time of Patient that is "QT-1 = 51.825 minutes" from average routine waiting time of "RT-1 = 73.925 minutes" [16]. We found in our study that average Doctor - Patient time that is time of interaction with Doctor during PAC in OPD clinic was also statistically significantly less in QT-2 (Group "Q") in comparison to RT-2 (Group "R").
Other authors have found similar observation [17 -19]. Spaite DWet al did rapid process redesign in a university-based emergency department. It helped in decreasing waiting time intervals and improving patient satisfaction. Similarly Adamu $\mathrm{H}$, Oche MO increased patient satisfaction with services at a general outpatient clinic of a tertiary hospital in Nigeria.

A questionnaire like ours was developed by W.G. Hildith, A.J. Asbury, E. Jack, S. Mcgrane. Harding $\mathrm{KE}$, Taylor NF which assessed satisfaction among allied health outpatients [20 -23]. As literatures alsosuggested that time spent with the physician is a stronger predictor of patient satisfaction than is the time spent in the waiting room. In one study Ranjeeta et al, who observed the consultation time to be $(6.6 \pm 3.7 \mathrm{~min})$ with $85.2 \%$ patients satisfied with such consultation. We found our results are in line with this finding. In the study done by Ranjeeta et al, the Doctor-Patient time always exceed this threshold, indicating the good satisfaction level among the patients registered for PAC in OPD clinic at our set up $[16,24]$.

\section{Conclusion}

Thus we found in our study with intervention used to reduce congestion in OPD in PAC clinic were effective and useful with indirect improvement of patient satisfaction. We found in our study the obvious reduction in overall "Waiting Time" in study Group "Q" than Group "R".

\section{What this study adds to existing knowledge}

Present study is planned to reduce congestion in OPD for pre-anesthesia checkup for elective surgery or procedure. Patient satisfaction comes automatically as a byproduct with the achievement of the goal of the study. Time is money in the present scenario and thus best utilization of time with efficient outcome is the prerequisite of any good management.

\section{Reference}

01. American Society of Anesthesiologists Task Force on Preanesthesia Evaluation. Practice advisory for preanesthesia evaluation- a report by the American Society of Anesthesiologists Task Force on Preanesthesia Evaluation. Anesthesiology. 2002 Feb;96(2)485-96.

[Crossref] 
02. Klopfenstein CE, Forster A, Van Gessel E. Anesthetic assessment in an outpatient consultation clinic reduces preoperative anxiety. Can J Anaesth. 2000 Jun;47(6)511-5.

DOI: $10.1007 /$ BF03018941 [Crossref]

03. Mendes FF, Mathias LA, Duval Neto GF, et al. Impact of preoperative outpatient evaluation clinic on performance indicators. Rev Bras Anestesiol. 2005 Apr;55(2)175-87.

[Crossref]

04. Barnes PK, Emerson PA, Hajnal $S$ et al. Influence of an anaesthetist on nurse-led, computer-based, pre-operative assessment. Anaesthesia. 2000;55;576-580.

[Crossref]

05. Organisation and Management of Hospitals. Practical Manual of PGDHHM 03. IGNOU- Patient satisfaction. 2001;14-25.

[Crossref]

06. Valentine NB, Silva A, Kawabata K, et al. Health system responsiveness- concepts, domains, and operationalization, In- CJL M, Evans DB, et al, editors, Health systems performance assessment- debates, methods and empiricism. Geneva- World Health Organization. 2003;96. [Crossref]

07. Silva A. A Framework for measuring responsiveness, GPE Discussion Paper SeriesNo 32, EIP/GPE/EBD. Geneva- World Health Organization. 2010.

[Crossref]

08. Michael $M$, Schaffer SD, Egan $P L$, et al. Improving wait times and patient satisfaction in primary care. J Healthc Qual. 2013 MarApr;35(2)50-59; quiz 59-60. doi: 10.1111/jhq.12004 [Crossref]

09. Katre AN. Assessment of the Correlation between Appointment Scheduling and Patient Satisfaction in a Pediatric Dental Setup. Int J Dent. 2014;1-7.

doi: $10.1155 / 2014 / 453237$ [Crossref]

10. Helbig M, Helbig S, Kahla-Witzsch HA, et al. Quality management: reduction of waiting time and efficiency enhancement in an ENT-university outpatients' department. BMC Health Serv Res. 2009;Jan 31;9;21.

doi: 10.1186/1472-6963-9-21 [Crossref]
11. Pitrou I, Lecourt AC, Bailly L, et al. Waiting time and assessment of patient satisfaction in a large reference emergency department- a prospective cohort study, France. Eur J Emerg Med. 2009 Aug;16(4)177-82.

doi: 10.1097/ME].0b013e32831016a6 [Crossref]

12. Anderson RT, Camacho FT, Balkrishnan R. Willing to wait?- the influence of patient wait time on satisfaction with primary care. BMC Health Serv Res. 2007 Feb $28 ; 7 ; 31$. DOI: $10.1186 / 1472-6963-7-31$ [Crossref]

13. Preyde $M$, Crawford $K$, Mullins $L$, et al. Patients' satisfaction and wait times at Guelph General Hospital Emergency Department before and after implementation of a process improvement project. CJEM. 2012 May;14(3)157-68.

[Crossref]

14. Harper PR, Gamlin HM. Reduced outpatient waiting times with improved appointment scheduling- a simulation modeling approach. OR Spectr. 2003;25;207-222.

doi: $\quad 10.1007 / \mathrm{s} 00291-003-0122-x \quad$ [Crossref]

15. Huang XM. Patient attitude towards waiting in an outpatient clinic and its applications. Health Serv Manage Res. 1994 Feb;7(1)2-8.

DOI: $10.1177 / 095148489400700101$ [Crossref]

16. Kumari $R$, Idris $M$, Bhushan $V$, et al. Study on patient satisfaction in the government allopathic health facilities of lucknow district, India. Indian J Community Med. 2009 Jan;34(1) 35-42. doi: 10.4103/0970-0218.45372 [Crossref]

17. Harshallowalekar and N. Ravichandran. Managing the outpatient department waiting time at rajas eye hospital. IMJ. 2012;Apr-Jun;4(1)36-46 [Crossref]

18. Mitrabasu, Predeep K Chugh, Amit Bardhan. Discrete event simulation to reduce patient waiting time in outdoor department of a tertiary care thyroid hospital. International Journal of Emerging Technology and Advanced Engineering. 2013; Sept 3(9)426- 431.

[Crossref] 
19. Pierce RA 2nd, Rogers EM, Sharp $M H$, et al. Outpatient pharmacy redesign to improve work flow, waiting time, and patient satisfaction. Am J Hosp Pharm. 1990 Feb;47(2)351-6.

[Crossref]

20. Spaite DW, Bartholomeaux F, Guisto J, et al. Rapid process redesign in a university-based emergency department- decreasing waiting time intervals and improving patient satisfaction. Ann Emerg Med. 2002 Feb;39(2)168-77.

[Crossref]

21. Adamu $H$, Oche MO. Patient satisfaction with services at a general outpatient clinic of a tertiary hospital in Nigeria. Br J Med Med Res. 2014;4(11)2181-2202.

doi: $10.9734 / B J M M R / 2014 / 5918$ [Crossref]
22. Hilditch WG, Asbury AJ, Jack E, et al. Validation of a pre-anaesthetic screening questionnaire. Anaesthesia. 2003 Sep;58(9)874-7.

[Crossref]

23. Harding KE, Taylor NF. Highly satisfied or eager to please?- Assessing satisfaction among allied health outpatients. Int J Ther Rehabil. $2010 ; 17(7) 353-359$.

doi: $\quad 10.12968 /$ ijtr.2010.17.7.48892 [Crossref]

24. Anderson RT, Camacho FT, Balkrishnan R. Willing to wait?- the influence of patient wait time on satisfaction with primary care. BMC Health Serv Res. 2007 Feb 28;7;31. DOI: $10.1186 / 1472-6963-7-31$ [Crossref] 